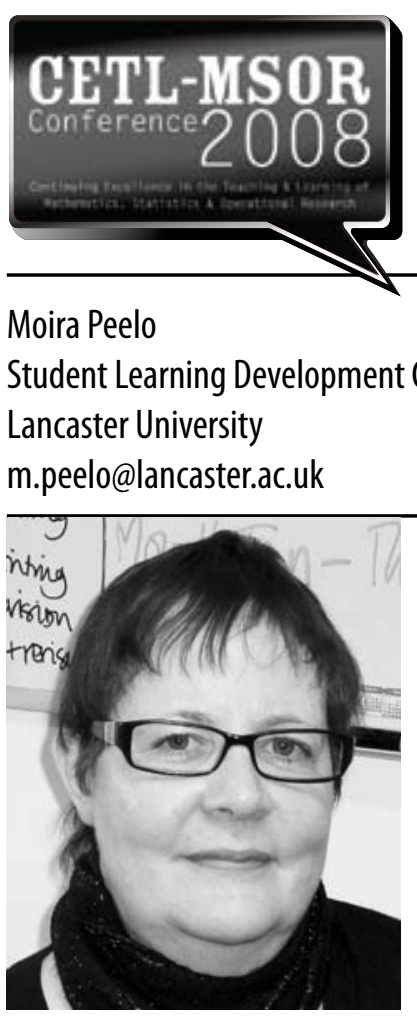

Brian Francis

Department of Maths and Statistics Lancaster University

b.francis@lancaster.ac.uk

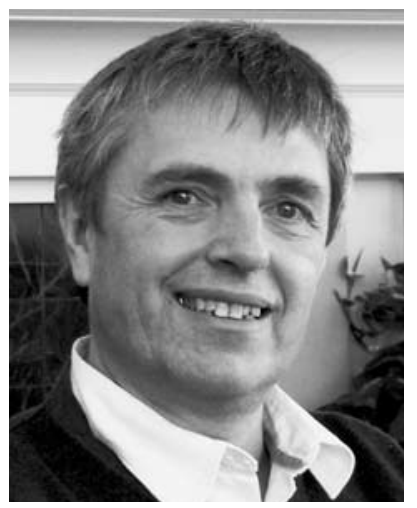

\section{Tackling mixed messages: embedding advanced numeracy in graduate identities}

Acknowledgements;

The authors are grateful for support from HEFCE through the Lancaster Centre

for Excellence in Teaching and Learning in Postgraduate Statistics, and the

Teaching Quality Enhancement Fund.

\begin{abstract}
This paper proposes some elements of a university-level agenda needed to develop a cross-campus approach to numeracy. In the last ten years, there has been much work supporting the development of pedagogy surrounding maths and quantitative skills alongside discussion and innovation in teaching elementary statistics, as well as growth of excellent websites. But there are additional barriers to numeracy in graduates which may not be a part of individual lecturers' remits and so are left unchallenged. We make the proposition that universities need to move beyond individual courses and degree schemes and start to think at institutional level in order to maximise the impact of innovations in maths and statistics teaching and learning to ensure that both specialist and non-specialist students are equipped to gain and maintain the employment that they want as graduates. Wider, cross-campus strategies can contribute both to raising awareness of the different constituencies and their teaching needs; and to tracking students' development in maths and quantitative work across degree schemes.
\end{abstract}

\section{Introduction}

Public concern about poor preparedness of students for post-school mathematics (for all subjects, not just specialist students) has been reflected in public reports over some years (for example, [1], [2], [3]). These concerns have been echoed in the HE sector, with concerns about improving teaching quantitative work across disciplines [4] reflected in the setting up of national Centres for Excellence in Teaching and Learning (CETLs) In the last ten years, there has been much work supporting the development of pedagogy surrounding maths and quantitative skills - the range of papers in the CETL-MSOR journal reflect the extensive amount of work individual lecturers put into teaching their own courses. A part of this upsurge of interest are the discussions and innovations in teaching elementary statistics ([5], [6]), as well as the growth of excellent websites such as the Statistics Online Computational Resource [7] [8], the Rice Virtual Statistics Laboratory [9] and the STatistical Education through Problem Solving (STEPS) project [10]. But is there a middle level, between national initiatives and the work of individual lecturers, that needs to be considered? To better support both specialist and non-specialist students, should we be working towards cross-campus agendas that attempt to embed a notion of numeracy in graduate identities?

There is a confused public narrative surrounding graduate skills in mathematical, numerical work: it is one that is both scathing of the perceived low-level of graduate skills plus one that is simultaneously forgiving of resistance to and dislike of anything numerical in otherwise highly qualified people. This public context helps blur messages intended to encourage all students to engage with a more positive identity in relation to quantitative work. 


\section{Public narrative on graduate numeracy}

Popularly, it is commonplace to question what 'basic skills' graduates now possess and whether these have declined over time - and to ask what graduates are qualified for [11]. What employers see as basic graduate skills, and what we require of students to complete their degrees are not necessarily the same, although employers' needs are highly likely to shape the public narrative surrounding graduate skills. So the head of a graduate recruitment firm was recently quoted as saying:'The more technical the degree, the worse the basic skills. Trying to find an IT specialist who can write a competent report, let alone one who has any interpersonal skills, is extraordinarily difficult' [12].

Yet, while it is commonplace to hear expressions of alarm if graduates' writing and grammar fall below popular expectations, there are nonetheless variable levels of public concern about the mathematical and quantitative capabilities of all graduates - with occasional suggestions that numerical proficiency is optional. Indeed, on occasions, the public narrative surrounding quantitative work can allow lack of appropriate numeracy to sound like a boast. So, for example, Jenkins argued recently in The Guardian for the irrelevance of his mathematical education, especially to the world of work [13]. Clarke asked in The Irish Times 'Why do erudite people boast of blissful ignorance of maths?' [14]. Garner recently discussed the failure of UK maths teachers to answer correctly basic numerical questions, under the headline -'Maths: does it matter?' [15]. In contrast, Clark in The Mail complained vehemently that'some graduates lack literacy and numeracy skills' [16].

While the worth of specialist degrees may be undermined by the public narrative that questions the value of all degrees and the basic skills of all graduates (see the IT example above), there is another facet of the public account about the lack of numeracy in non-specialist graduates that is familiar - that of the fear of maths. This is often linked to the low level of numeracy in non-specialist graduates (e.g. arts or social science students). So, for example, under the heading 'The fear of all sums', Guardian journalist Matt Keating described the need for a'numeracy-savvy workforce' at all levels [17], while describing a CBI survey in 2007 which reported that amongst employers 'one in five were less than happy with the numerical competence of graduates'.

These examples illustrate some prevalent narratives surrounding graduate numeracy that help shape the context within which CETL initiatives and individual lecturers' initiatives take place - providing a complex arena for those initiatives to bring about change. Hence, this paper raises the question: what can be done at institutional level to support the embedding of numerical and quantitative skills' development in all graduate identities?

\section{Institutional agendas?}

So, how do we begin to make sense of what an institutional agenda might look like? In the first instance, we would argue, is the need to (1) to make a clear analysis of need by raising awareness of the different constituencies and their teaching needs. Second, to (2) develop a mindset in which all students' quantitative work is treated as a coherent whole, both by (i) tracking students' development in maths and quantitative work across modules and courses in degree schemes as a matter of routine; and by (ii) encouraging students to monitor their own development.

\subsection{Constituencies}

Different groups have different needs (Fig 1), yet also have some common teaching and learning concerns, such as: resourcing, popularity of courses, retaining students and their interest, encouraging students to see the need for specific knowledge and skills in their lives. Innovation in one area may hold the germ of ideas for innovation in teaching in another; how to accredit skills acquisition in one area of the university may be a problem that has been tackled elsewhere. Networks that access such commonality are easier to set up where quantitative work is most evidently a part of a teaching portfolio (as in $\mathrm{C}$ and $\mathrm{D}$ below), but two areas are more problematic because they fall outside most traditional courses: (a) Entry to work - psychometric tests and qualifications for teaching. While these are not, strictly speaking, entirely numerical matters, nonetheless fear of maths can affect how individuals approach logic and reasoning tests plus low-level arithmetic (at whatever level they left formal maths teaching) and (b) numeracy for life - e.g. spreadsheets, basic arithmetic, budgets, mortgages, and loans.

\section{Constituencies?}

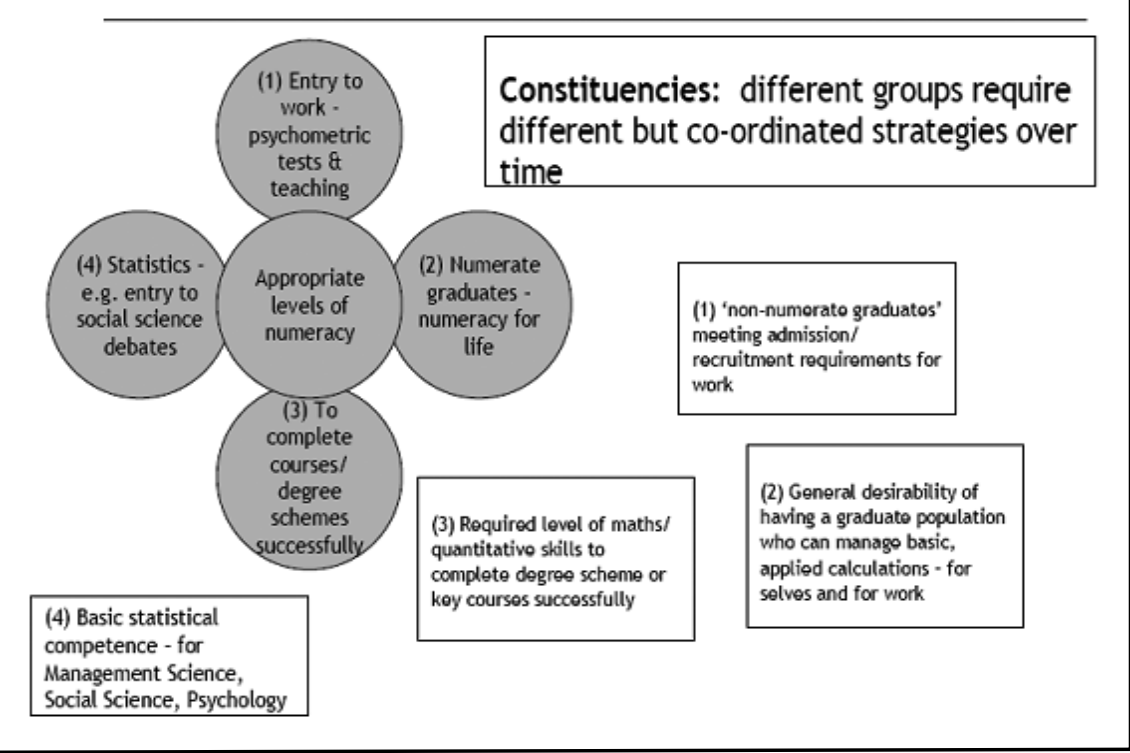

Fig 1 - Constituencies of university students with differing numeracy needs 
Much more familiar are those sets of needs that may be found within traditional modules: (c) to complete maths or quantitative work as an integral part of graduating successfully from a degree scheme; and (d) statistics (from accessing basic social science debates through to more complex and subject-specific research courses). The needs of each group are not immediately clear: as most lecturers find in subjects across universities, there is great variability in skill and capability within each course - presenting challenging teaching and curriculum design problems. This is the same in non-specialists groups, for example Fritz et al [5] have said:

\section{"Social science students vary widely in their preparedness} for quantitative topics. Although many students have avoided quantitative study beyond the minimum required at GCSE level, others have excellent A-level doublemathematics marks. Among the students with the lowest qualifications there are likely to be some with dyscalculia."

It is not uncommon for disparate sets of lecturers to address similar problems in isolation from each other. Not all institutions or regions are fortunate enough to have a CETL to organise seminars, but even these are unlikely to address more basic questions about, for example, resourcing, retention or suitability of teaching accommodation.

\subsection{Tracking across modules}

Raising the profile of appropriate numeracy at an institutional level starts with showing how, as educationalists, we take it seriously as a coherent and essential part of students' graduate identities; however, structural elements in higher education can make this difficult to achieve. In an age of modular degree schemes, this can require extra effort especially in non-mathematical specialisms.

As long ago as 1976, the benefits of modular degree schemes were summarised by Burge [18]: especially that they allow flexibility and the chance for students to choose combinations of interests to study. However, the problems that can be attached to modular degree schemes have also been much discussed, some of which were summarised by Charlton [19]

"Organising the curriculum in discrete modules damages cohesion and intellectual progression, teaching is less integrated and less intense, and it takes longer to bring students to the same level of specialist expertise." (p.4)

Barron [20] has, further, commented on the impact of fourcourse semesters on international students, encouraging a superficial approach that drops subject matter once the semester has been assessed, so "the opportunity for deeply processing material over time is not afforded to students". (p. 20)

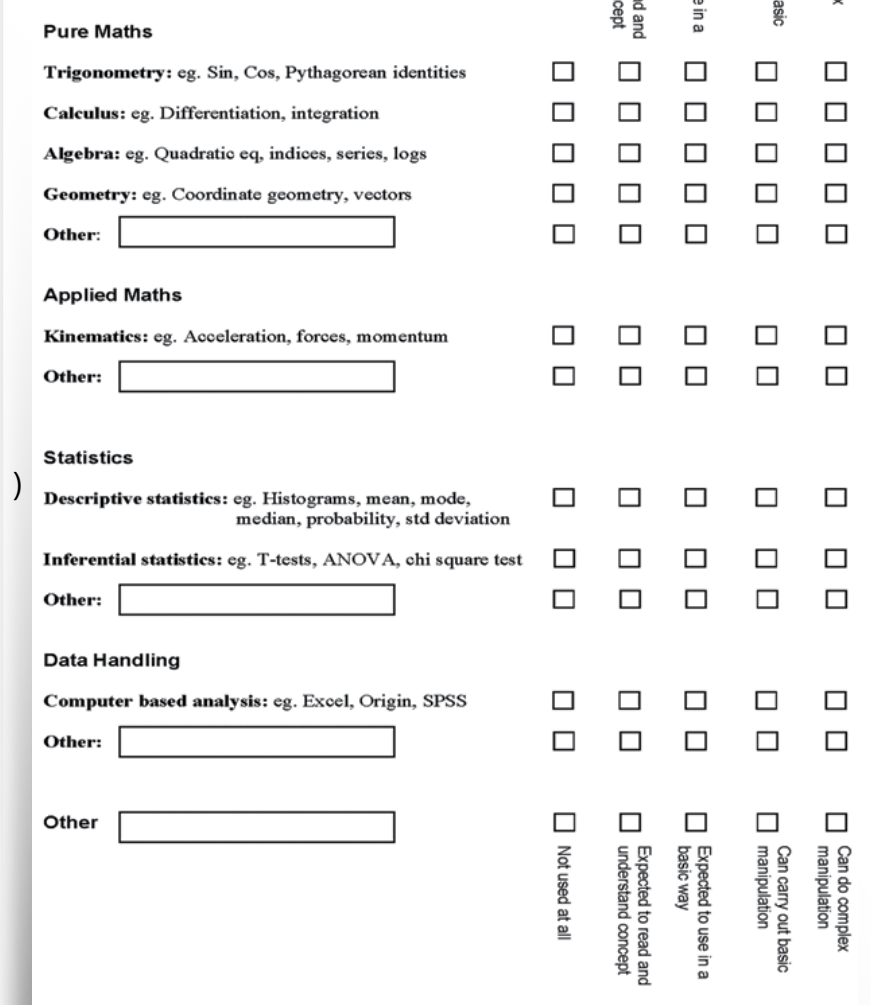

Fig 2 - A student record of maths skills for each module taken

We include an example in Fig 2 of one possible form ${ }^{1}$ which we designed to be used as the basis for encouraging students - perhaps with tutors - to learn to map what skills and capabilities are being developed on which courses; and, perhaps equally as important, for designers of degree schemes to chart which topics come in what order in relation to each other.

\subsection{Students' reflection on their academic development}

Fig 3 and 4 show possible template forms which could be interpreted as part of a wider trend to engage students in personal development planning which has reflection as an integral first step. McAlinden [21] has shown how effectively personal development planning (PDP) activities can be integrated into a specific mathematics module. Integration into particular modules seems, for many pedagogic reasons, highly desirable. But where institutions offer a generalised, cross-campus option, should we be encouraging colleagues to include specific reflection on students' numerical development?

This paper is hypothetical - it does not offer a model of what is needed to begin to change the comfortably non-numerate nature of the public narrative surrounding graduate identity; but instead imagines some practical elements that might be part of a university-level agenda intended to begin to take such an approach. The pragmatic examples provided are designed to contribute to raising awareness of students' numerical and mathematical 
development as a coherent part of their graduate identities rather than just as a series of discrete skills and activities. We make the proposition that universities need to move beyond individual courses and degree schemes and start to think at an institutional level in order to maximise the impact of innovations in maths and statistics teaching and learning to ensure that both specialist and nonspecialist students are equipped to gain and maintain the employment that they want as graduates. In offering these examples, we hope to raise the debate and to hear what others are already doing in relation to what we have called the 'institutional agenda.

\section{"The pragmatic examples provided are designed to contribute to raising awareness of students' numerical and mathematical development as a coherent part of their graduate identities rather than just as a series of discrete skills and activities."}

Keeping a log: developing maths \& quantitative skills

Why would I keep a log?

University rushes by and what you struggle with today can become a distant memory quite soon. So reviewing and reflecting on quantitative work in your degree scheme by keeping a log can:

Aid memory by reviewing progress throughout university;

Keep track of how you met different challenges;

It's invaluable to have examples of academic challenges you have overcome when applying for work; and provides an easy-to-access record of what you've learnt and how you learnt it.

What would I put in a log?

Information that you record depends on your own interests and ambitions, but below are some examples of questions and a form for helping you review progress:

Examples of questions you could ask yourself

Example of a form to use for each module or course
Fig 4 - Example of personal review of Maths skills for each module 


\section{References}

1. London Mathematical Society (1995) Tackling the Mathematics Problem. Royal Statistical Society: London. Available via: http://www.Ims.ac.uk/policy/tackling_ maths_prob.pdf

[Accessed 5 November 2009].

2. Savage, M.D. and Hawkes, T. (2000) Measuring the Mathematics Problem. Engineering Council: London. Available via: http://www.engc.org.uk/ ecukdocuments/internet/document\%20library/ Measuring\%20the\%20Mathematic\%20Problems.pdf [Accessed 5 November 2009].

3. Sutherland, R. and Dewhurst, H. (1999) Mathematics Education Framework for Progression from 16-10 to HE. University of Bristol Graduate School of Education.

4. Francis, B., Abram, B. and Peelo, M (2007). The Lancaster Postgraduate Statistics Centre: CETL: building trust and statistical skills across disciplines. In Green, D. CETLMSOR Conference Proceedings 2006:60-62. Available via: http://www.mathstore.ac.uk/conference2006/ Final\%20Proceedings\%202006/Conference $\% 20$ Proceedings_WEB.pdf. [Accessed 5 November 2009].

5. Fritz, C., Peelo, M., Folkard, A., Ramirez-Martinell, A. (2008) 'Quantitative skills in the social sciences: identifying and addressing the challenges'. In Green, D. (ed). CETL-MSOR Conference Proceedings 2007:34-40. Available via: http://www.mathstore.ac.uk/repository/ CETLMSOR2007_Proceedings.pdf [Accessed 5 November 2009].

6. Kynn M. and Abram B.(2007) 'Experiences in teaching masters psychology students: formative vs summative assessment' In Green, D. CETL-MSOR Conference Proceedings 2006:97-102. Available via: http://www.mathstore.ac.uk/conference2006/Final\%20 Proceedings\%202006/Conference\%20Proceedings_ WEB.pdf [Accessed 5 November 2009].

7. Ivo D. Dinov, Juana Sanchez and Nicolas Christou. (2008) Pedagogical Utilization and Assessment of the Statistic Online Computational Resource in Introductory Probability and Statistics Courses, Journal of Computers \& Education, 50: 284-300.

8. Statistics Online Computational Resource (SOCR) website. Available via: http://www.socr.ucla.edu/ [Accessed 5 November 2009].

9. Lane, D (2008) Rice Virtual Statistics Laboratory website. Available via: http://onlinestatbook.com/rvls. html [Accessed 5 November 2009].

10. Statistical Education through Problem Solving (STEPS) website. Available via: http://www.stats.gla.ac.uk/ steps/ [5 November 2009].

11. EXEC (2008) Inside the graduate recruitment market: qualified for nothing? 11 February.
12. Management Today (1997) 'UK:Cant spel, don't kare'. 1st March 1997. Available via: http:managementtoday. co.uk/search/article/406893/uk-cant-spel-don't-kare/ [Accessed 5 November 2009].

13. Jenkins, S. (2008) 'Maths? I breakfasted on quadratic equations, but it was a waste of time' The Guardian, 6 June 2008. Available via: http://www.guardian.co.uk/ commentisfree/2008/jun/06/maths.alevels [Accessed 5 November 2009].

14. Clark, D. (2008) 'Why do erudite people boast of blissful ignorance of maths?' The Irish Times, 16 August 2008. Available via: http://www.irishtimes.com/newspaper/ opinion/2008/0816/1218748037830.html [Accessed 5 November 2009].

15. Garner, R. (2008) Maths - does it matter? The Independent Education section. 7 June 2008. Available via: http://www.independent.co.uk/ news/education/education-news/maths-does-itmatter-842114.html [Accessed 5 November 2009].

16. Clark, L. (2008)'The graduate divas: Bosses mourn arrival of Generation Y, the graduate diva[s who want it all'. The Mail, 31.January 2008. Available via: http://www. dailymail.co.uk/news/article-511379/The-graduatedivas-Bosses-mourn-arrival-Generation-Y-graduatedivas-want-all.html [Accessed 5 November 2009].

17. Keating, M. (2007) 'The fear of all sums'. Available via: http://www.guardian.co.uk/money/2007/oct/13/work [Accessed 5 November 2009].

18. Burge, E.J. (1976) 'Modular courses and degree structures'. Physics Education, May 1976, 11: 137-141. Available via: http://www.iop.org/EJ/abstract/0031-9120/11/3/001 [Accessed 5 November 2009].

19. Charlton, B. (2003) 'The educational purpose of multidisciplinary modular degrees'. Oxford Magazine. 212: 4-6.

20. Barron, P. (2008) 'Learning approaches and learning styles' (pp. 19-20) in: (ed.) Foster, M. Enhancing the Experience of Chinese Students in UK Higher Education - Lessons from a Collaborative Project. SEDA Special 23: London.

21. McAlinden, M. (2007) 'A structured approach to incorporating personal development planning into a mathematics module.' assessment' In Green, D. CETLMSOR conference proceedings 2006:108-112. Available via: http://www.mathstore.ac.uk/conference2006/ Final\%20Proceedings\%202006/Conference $\% 20$ Proceedings_WEB.pdf [Accessed 5 November 2009].

\section{Notes to article}

1 Becca Whitehead \& Moira Peelo, Lancaster Maths Project: http://www.lancs.ac.uk/depts/celt/sldc/maths/ teaching/teachingsupport.html see: 'Course design form'. 